\title{
Hydrodynamic effect on the superlubricity of phosphoric acid between ceramic and sapphire
}

\author{
Mingming DENG ${ }^{1}$, Chenhui ZHANG ${ }^{1,2,}$, Jinjin LI $^{1}$, Liran MA ${ }^{1}$, Jianbin LUO ${ }^{1}$ \\ ${ }^{1}$ State Key Laboratory of Tribology, Tsinghua University, Beijing, 100084, China \\ ${ }^{2}$ Shenzhen Key Laboratory of Micro-Nano Manufacturing, Research Institute of Tsinghua University in Shenzhen, Shenzhen, 518057, China \\ Received: 16 May 2014 / Accepted: 26 May 2014 \\ (C) The author(s) 2014. This article is published with open access at Springerlink.com
}

\begin{abstract}
In this work, a super-low friction coefficient of 0.003 was found between a silicon nitride ball and a sapphire plate lubricated by phosphoric acid solution. The wear mainly occurred in the running-in period and disappeared after superlubricity was achieved. The friction coefficient was effectively reduced from 0.3 to 0.003 at a constant speed of $0.076 \mathrm{~m} / \mathrm{s}$, accompanied by a 12-nm-thickness film. The lubrication regime was indicated to change from boundary lubrication in the running-in period to elastohydrodynamic lubrication in the superlubricity period, which is also supported by the results of the friction coefficient versus sliding speed. In addition, the experimental results showed good agreement with theoretical calculations based on the elastohydrodynamic lubrication theory, suggesting a significant hydrodynamic effect of phosphoric acid on superlubricity.
\end{abstract}

Keywords: liquid superlubricity; phosphoric acid; hydrodynamic lubrication; film thickness

\section{Introduction}

"Superlubricity" has been put forward to describe the ultra-low friction state between two contacted surfaces [1]. Nowadays, this term refers to any frictional situation with a friction coefficient lower than 0.01 [2]. Superlubricity achieved by solid-solid contacts and across liquid media have both been reported in the past several decades. Molybdenum disulfide was the first identified example of solid superlubricity; it was found to have a super-low friction coefficient of $0.001[3,4]$. Subsequently, diamond-like carbon [5, 6], graphite [7] and carbon nitride coating [8,9] were used to achieve superlubricity under vacuum, in a humid atmosphere and in a nitrogen atmosphere, respectively. Recently, carbon nanotubes were reported to display excellent superlubricity performance in an atmospheric environment [10]. The reported solid superlubricity performances have been attributed

* Corresponding author: Chenhui ZHANG.

E-mail: chzhang@tsinghua.edu.cn mainly to the combination of effects from incommensurate contact, weak interfacial interaction, and coulomb repulsion [11-13]. In contrast, less attention has been paid to liquid superlubricity. Ceramics $\left(\mathrm{Si}_{3} \mathrm{~N}_{4} / \mathrm{Si}_{3} \mathrm{~N}_{4} / \mathrm{SiC}\right)$ lubricated by water were first used to achieve superlubricity on the macroscale $[14,15]$. Using a surface force apparatus (SFA), which is the basis for studies of hydration lubrication [16], confined salt solutions between mica surfaces were found to provide superlubricity performance in nanogaps. Based on this concept, polyelectrolytes with polymer brush appearances were also found to possess a super-low friction coefficient when sliding in water [17]. The superlubricity of other liquids, including the mixture of glycerol and acid [18] and some biological mucilage $[19,20]$, has also been reported in recent years. Unlike solid superlubricity, the mechanism of liquid superlubricity is still debated. Concepts including elastic hydrodynamic lubrication (EHL) [21], electric double-layer force [22], and hydration lubrication [23] have been utilized to explain the mechanism of liquid superlubricity. 
Recently, the superlubricity of phosphoric acid solution between ceramic and glass was reported by Li et al. [24]. This property was explained by the formation of a hydrogen bond network composed by phosphoric acid and water molecules [25]. In the case of ceramics coming into contact with water, the hydrodynamic effect might also play an important role [21]. A comprehensive understanding of this type of superlubricity system is lacking.

In this work, the friction behavior of a phosphoric acid solution between a silicon nitride ball and a sapphire plate was investigated. With the aim to illuminate the hydrodynamic effect on the formation of superlubricity in the system, both measurements of film formation and theoretical calculations have been carried out.

\section{Experimental section}

The phosphoric acid solution with a $\mathrm{pH}$ value of 1.5 was prepared by dissolving phosphoric acid (purity $\geqslant 90 \%$ ) in deionized water (resistivity $>18 \mathrm{M} \Omega \cdot \mathrm{cm}$ ). The viscosities of the phosphoric acid solutions with different concentrations were measured using a capillary viscometer.

The friction pairs were composed of a 4-mmdiameter silicon nitride ball and a sapphire plate. The surface roughnesses of the silicon nitride ball and the sapphire plate were $1.2 \mathrm{~nm}$ and $5.9 \mathrm{~nm}$, respectively. The mechanical properties of the sapphire and silicon nitride ceramic are shown in Table 1.

Tribology experiments were performed in ball-ondisk mode using a universal micro-tribotester (UMT-3). Before friction surfaces came into contact with each other, a drop $(10 \mu \mathrm{L})$ of phosphoric acid solution $(\mathrm{pH}=$ 1.5) was confined between the silicon nitride ball and the sapphire plate. A load of $1.5 \mathrm{~N}$ was then applied, providing the maximum Hertz contact pressure of 1.377 GPa. The rotational velocity of the sapphire plate

Table 1 Mechanical properties of the silicon nitride/sapphire ceramic.

\begin{tabular}{lcc}
\hline \multicolumn{1}{c}{ Material } & $\mathrm{Si}_{3} \mathrm{~N}_{4}$ & Sapphire \\
\hline Density $\rho\left(\times 10^{3} \mathrm{~kg} / \mathrm{m}^{3}\right)$ & 3.3 & 3.98 \\
Vickers hardness $H_{\mathrm{v}}(\mathrm{GPa})$ & 14.2 & 17.6 \\
Young's modulus $E$ & 310 & 410 \\
Poisson's ratio $v$ & 0.26 & 0.27 \\
\hline
\end{tabular}

ranged from 1 to $480 \mathrm{rpm}$ to create a sliding speed from 0.0004 to $0.2 \mathrm{~m} / \mathrm{s}$ at a track radius of $4 \mathrm{~mm}$. All friction tests were carried out at ambient temperature $\left(20{ }^{\circ} \mathrm{C}\right)$ and a relative humidity of $\sim 30 \%$.

Before and after the friction test, the summed weight of the sapphire plate, the $\mathrm{Si}_{3} \mathrm{~N}_{4}$ ball and the phosphoric acid droplet was measured using an electronic balance (ME36S) with an accuracy of $0.00001 \mathrm{~g}$ to obtain the concentration of the solution during the friction process. The topographies of the friction surfaces were investigated by white light interferometer (MICROXAM-3D) and optical microscope (Olympus). Furthermore, the wear region was investigated with an atomic force microscope (Nanoman VS).

Film thickness was measured on equipment designed based on relative optical interference intensity (ROII) [26], as shown in Fig. 1. The sapphire plate was rotated with a speed ranging from $0.006 \mathrm{~m} / \mathrm{s}$ to $0.1 \mathrm{~m} / \mathrm{s}$, and a load of $1.5 \mathrm{~N}$ was applied between the ball and the plate. The upper surface of the sapphire plate was coated by an anti-reflection film. The reflectivity at the sapphire/phosphoric acid interface was $2.5 \%$, and that at the silicon nitride/phosphoric acid interface exceeded 3\%. When a monochromatic light beam with a 600-nm-wavelength arrives at the interface of sapphire plate and phosphoric acid, it is divided into two interferential beams that are separately reflected

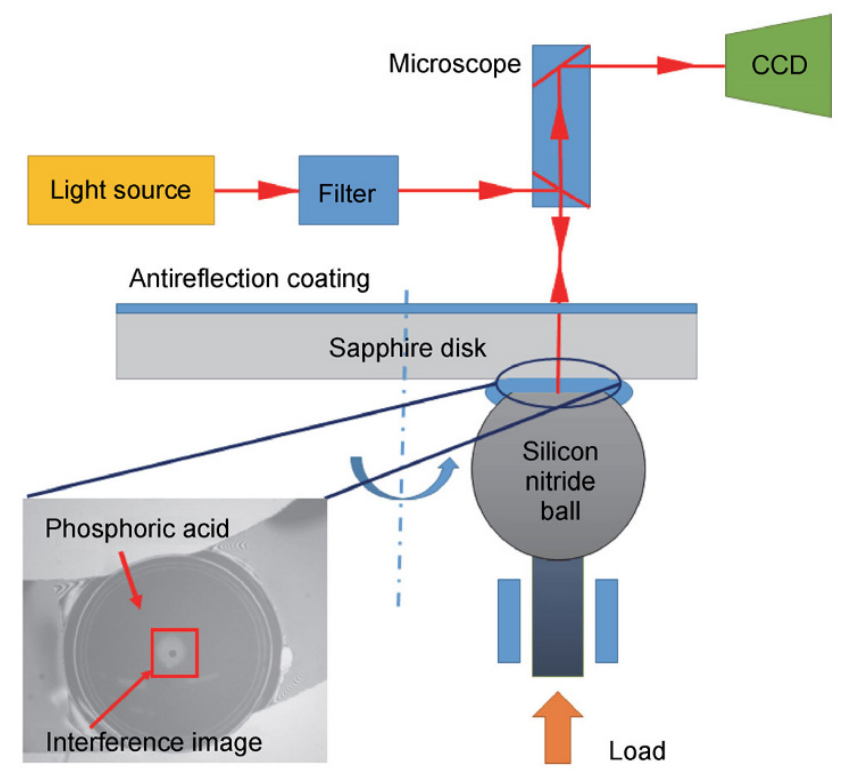

Fig. 1 Schematic diagram of ball-on-disk geometry to measure the film thickness and observe the contact region. 
by the surfaces of the sapphire plate and the $\mathrm{Si}_{3} \mathrm{~N}_{4}$ ball. $I_{1}$ and $I_{2}$ represent the light intensity values of two beams. Interference fringes are formed and digitized in the charged-coupled device camera (CCD) (Fig. 1). The expression for the measured interference intensity I was proposed in Ref. [26],

$$
I=I_{1}+I_{2}+2 \sqrt{I_{1} I_{2}} \cos \left(\frac{4 \pi k h}{\lambda}+\Phi\right)
$$

where $h$ is the film thickness between the sapphire plate and the silicon nitride ball, $\lambda$ is the wavelength of light, $k$ is the refraction index of phosphoric acid and $\Phi$ is the optical path difference at $h=0$.

If the interference intensity $I$ at the contact region is measured, the film thickness can be derived by Eq. (2) [26],

$$
h=\frac{\lambda}{4 \pi k}\left[\left(n+\left|\sin \frac{n \pi}{2}\right|\right) \cdot \pi+\arccos (\bar{I}) \cdot \cos n \pi-\arccos \left(\overline{I_{0}}\right)\right]
$$

where $n$ is the optical fringe order and $\bar{I}=$ $\frac{2 I-\left(I_{\max }+I_{\min }\right)}{I_{\max }-I_{\min }}$ is the relative optical intensity, in which $I_{\max }$ and $I_{\min }$ represent the maximum and minimum interference intensities, respectively.

\section{Results and discussion}

Figure 2 shows the friction coefficient of the phosphoric acid solution $(\mathrm{pH}=1.5)$ between the silicon nitride ball and the sapphire plate as a function of time. The friction coefficient was reduced from 0.25 to 0.04 after about $250 \mathrm{~s}$; it was then rapidly reduced further to 0.003 in the following $20 \mathrm{~s}$. Subsequently, the superlow friction state $(\mu=0.003)$ can last for more than $6 \mathrm{~h}$, indicating that the state of superlubricity is very stable. Thus, the friction process can be divided into two periods: the running-in period ( $\sim 300 \mathrm{~s})$ and the superlubricity period.

Notably, the concentration of the phosphoric acid solution gradually changed with time due to the evaporation of water, as shown in Fig. 3(a). The concentration changes rapidly in the running-in period and keeps at a constant value of $80 \%$ for at least $30 \mathrm{~min}$ in the superlubricity period; this region of steady concentration is associated with steady friction in the superlubricity period. The viscosity of lubrication was also measured at different phosphoric acid concentrations, as shown in Fig. 3(b). The viscosity at the beginning of the experiment is almost equal to water; it then increases rapidly during the running-in period and maintains a constant value of $25 \mathrm{mPa} \cdot \mathrm{s}$ (10 times that of the beginning value) during the superlubricity period.

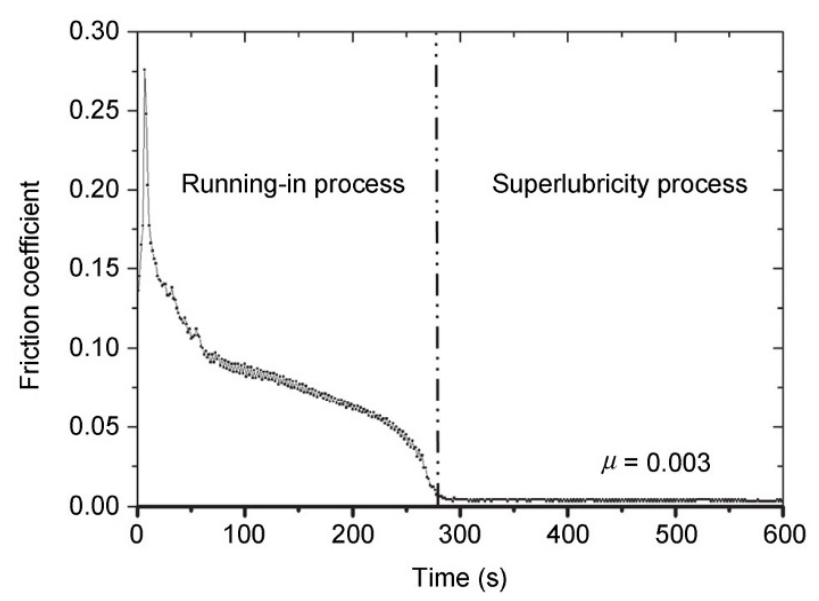

Fig. 2 Friction coefficient of phosphoric acid $(\mathrm{pH}=1.5)$ as a function of time. The load is $1.5 \mathrm{~N}$ and the sliding speed is $0.076 \mathrm{~m} / \mathrm{s}$.

(a)
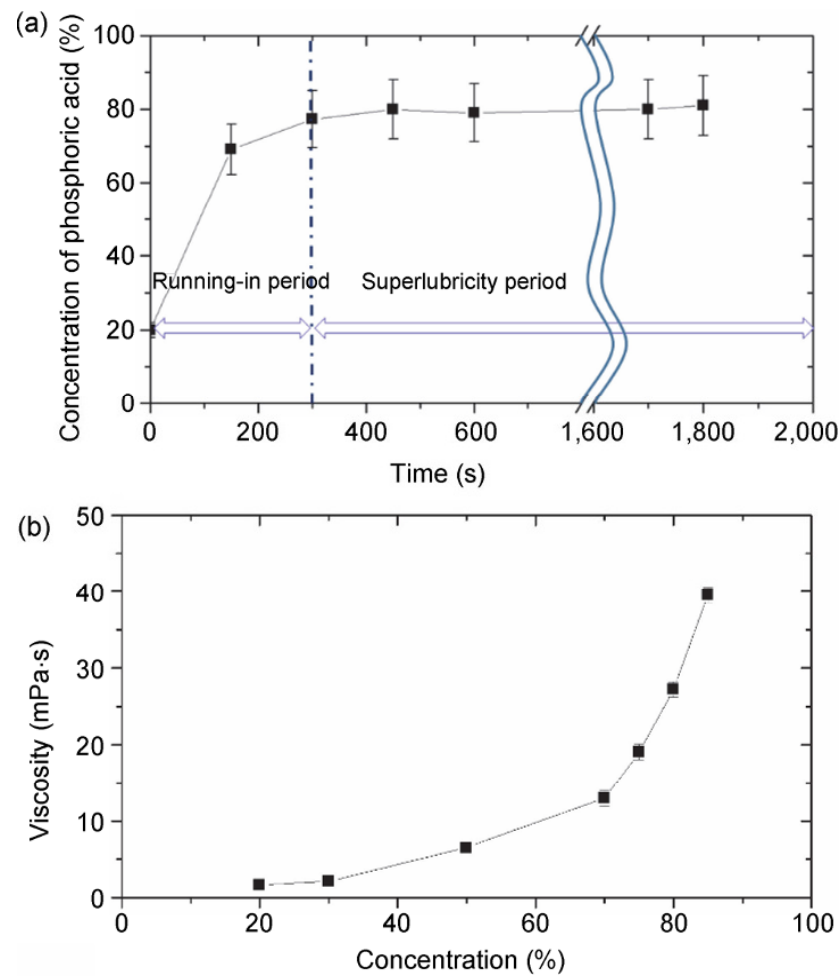

Fig. 3 (a) The concentration of phosphoric acid solution measured as a function of time at a load of $1.5 \mathrm{~N}$ and a speed of $0.076 \mathrm{~m} / \mathrm{s}$; (b) the viscosity as a function of the concentration. 
After the friction test, the three-dimensional topographies of the friction pairs were measured after being cleaned in an ultrasonic bath with acetone, ethanol, and deionized water (15 min each; Figs. 4(a) and $4(\mathrm{~b}))$. The sapphire plate has some scratches with depths of $5 \mathrm{~nm}$ and widths less than $1 \mu \mathrm{m}$. On the silicon nitride ball, a $90 \mu \mathrm{m}$ worn area is formed, reducing the contact pressure from $1.377 \mathrm{GPa}$ to $0.352 \mathrm{GPa}$. Atomic force microscopy (AFM) was also used to gain detailed information about the friction surfaces. As shown in Figs. 4(c) and 4(d), the actual widths of the scratches on the sapphire plate are several hundred nanometers, and the depth is several nanometers. Many particles with diameters around $100 \mathrm{~nm}$ are observed on the worn surface of the silicon nitride ball. This suggests that the scratches on the sapphire plate are due to the plowing effect that occurs between the particles and the sapphire plate, which occur mostly during the running-in period. Furthermore, the surface roughness of the sapphire plate is reduced from $1.2 \mathrm{~nm}$ to $0.3 \mathrm{~nm}$ upon achievement of superlubricity. Similarly, the roughness of the silicon nitride ball is reduced from $5.9 \mathrm{~nm}$ to $3.1 \mathrm{~nm}$. These results suggest that the running-in process has the effect of reducing the roughnesses of the rubbing surfaces.
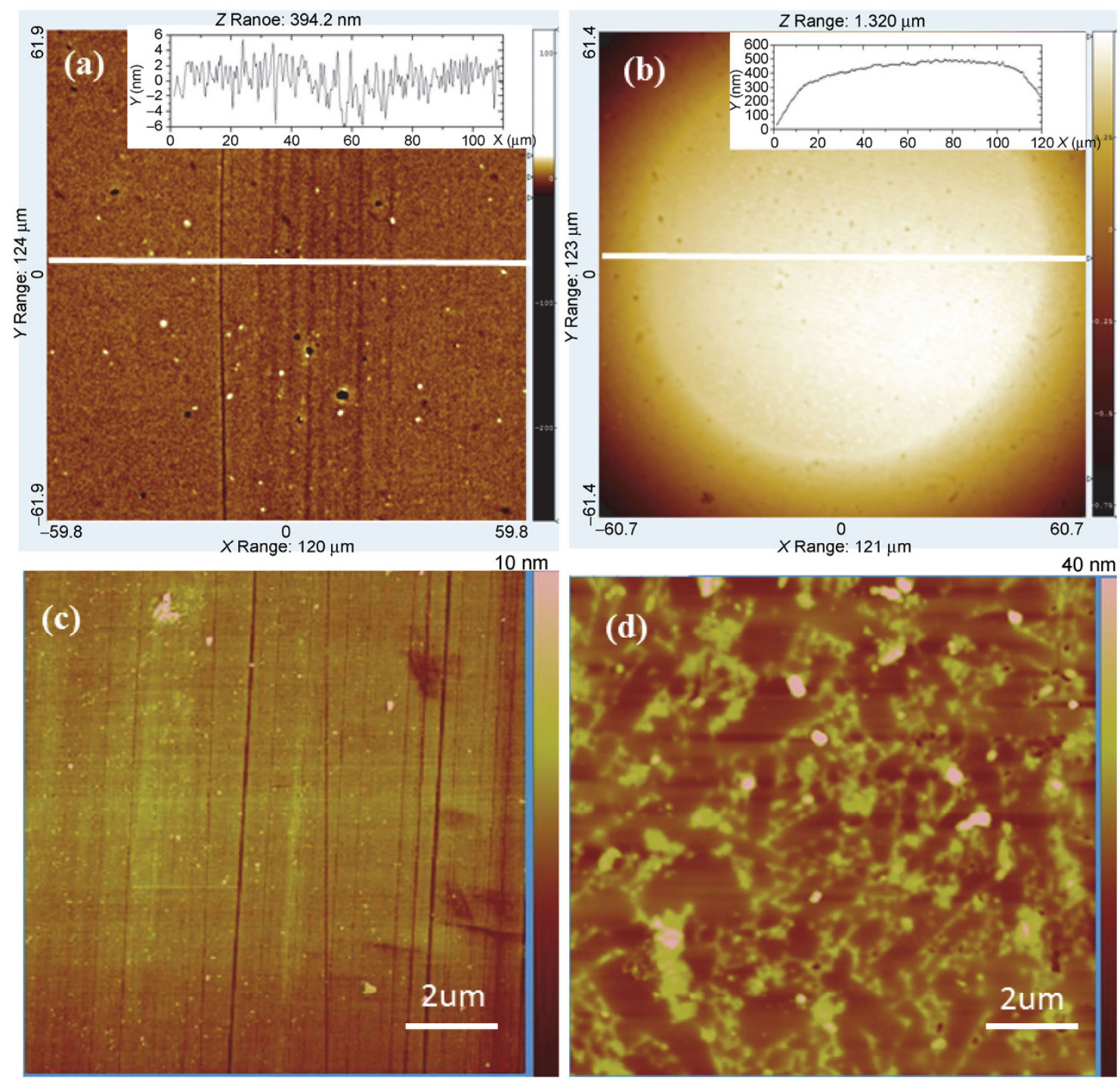

Fig. 4 The topography of friction pairs when superlubricity was achieved under sliding speed $=0.076 \mathrm{~m} / \mathrm{s}$ and load $=1.5 \mathrm{~N}$ using phosphoric acid as lubricant. (a) Sapphire plate by phase shift microxam-3D, (b) silicon nitride ball by phase shift microxam-3D, (c) sapphire plate by AFM, and (d) silicon nitride ball by AFM. 
The contact area between the sapphire plate and the silicon nitride ball was recorded online using the direct observation equipment sketched in Fig. 1. As shown in the illustration in Fig. 5, the inner circle indicates the contact area. By measuring the diameter of the inner interference circle, the diameter of the contact area was plotted as a function of time. The diameter changes rapidly from $52 \mu \mathrm{m}$ to $80 \mu \mathrm{m}$ in the first $80 \mathrm{~s}$; it then increases slowly until superlubricity is achieved. In the superlubricity period, the diameter of the contact area is constant at $90 \mu \mathrm{m}$, which is in agreement with the dimension of the worn region on the silicon nitride ball.

The interference images at different times were also recorded, as shown in Fig. 6. At $100 \mathrm{~s}$, a bright tail appears at the outlet region of the contact area; its size increases with time until $300 \mathrm{~s}$. After that, the bright tail is constant for at least $5 \mathrm{~h}$. This bright tail results from the negative pressure induced by the hydrodynamic effect, which has been reported by Choo et al. [27]. These results suggest that the hydrodynamic effect becomes significant as time goes by.

According to EHL theory, the viscosity at the beginning of the test is too small $(\sim 1 \mathrm{mPa} \cdot \mathrm{s}$; Fig. 3$)$ to form effective hydrodynamic films under such high pressure $(1.377 \mathrm{GPa})$ and low sliding speed $(0.012 \mathrm{~m} / \mathrm{s}-$ $0.2 \mathrm{~m} / \mathrm{s}$ ). Taking the surface roughness of the silicon nitride ball and the sapphire plate into account, the boundary lubrication is expected to be the dominant mechanism at the beginning of the friction. As the time goes by, a smoother, worn surface forms on the

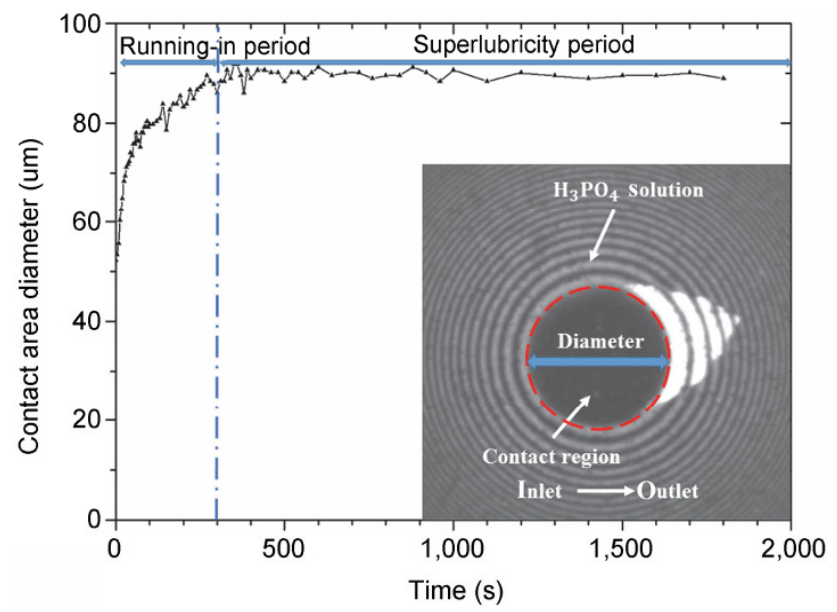

Fig. 5 The diameter of contact area as a function of time measured by the technique of relative optical interference intensity under sliding speed $=0.076 \mathrm{~m} / \mathrm{s}$ and load $=1.5 \mathrm{~N}$.
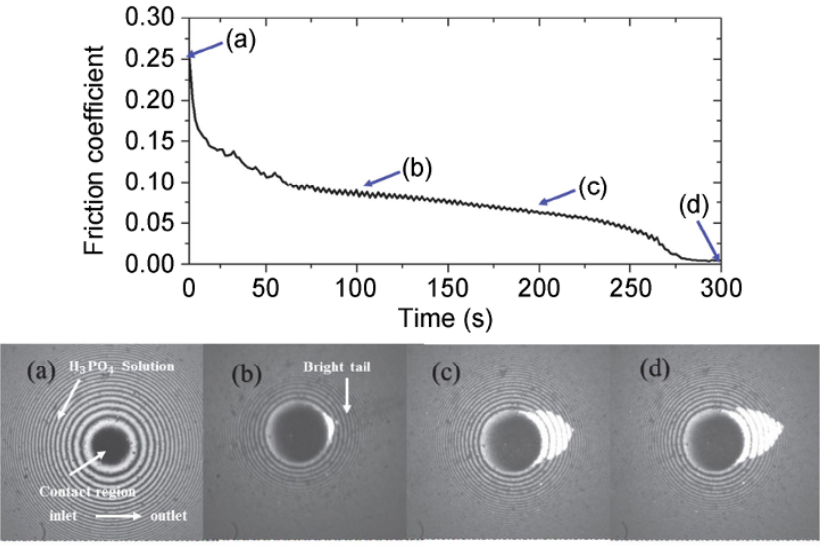

Fig. 6 The images of the contact (load $=1.5 \mathrm{~N}$, sliding speed $=$ $0.076 \mathrm{~m} / \mathrm{s}$ ). (a) $0 \mathrm{~s}$, (b) $100 \mathrm{~s}$, (c) $200 \mathrm{~s}$, and (b) $300 \mathrm{~s}$.

silicon nitride ball to reduce the contact pressure to $0.352 \mathrm{GPa}$ and the viscosity of the lubricant increases to $25 \mathrm{mPa} \cdot \mathrm{s}$. In this case, the elastohydrodynamic film may be established in the superlubricity period.

For EHL, sliding speed is one of the key parameters affecting the lubrication state and friction coefficient. To investigate the hydrodynamic effect on the superlubricity of phosphoric acid solution, the friction coefficient and film thickness of phosphoric acid as a function of sliding speed were measured using UMT3 and the ROII method, respectively (Fig. 7). With
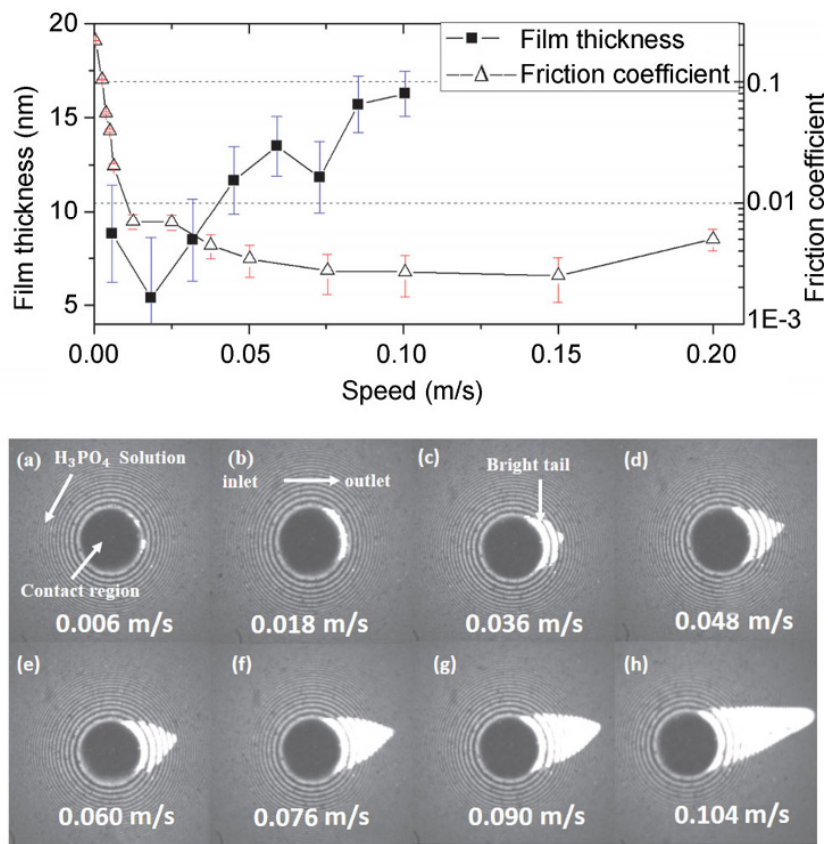

Fig. 7 The film thickness of phosphoric acid solution $(\mathrm{pH}=1.5)$ measured as a function of sliding speed, compared with the friction coefficient (a)-(h) is corresponding to the interference images under different speed $($ Load $=1.5 \mathrm{~N})$. 
increasing sliding speed, the friction coefficient first decreases from 0.3 to 0.003 (sliding speed $<0.15 \mathrm{~m} / \mathrm{s}$ ), and then increases to 0.005 (sliding speed $=0.2 \mathrm{~m} / \mathrm{s}$ ). Superlubricity can be achieved when the sliding speed is larger than $0.012 \mathrm{~m} / \mathrm{s}$. The curve of the friction coefficient vs. sliding speed is similar to the Stribeck curve, which is an important characteristic of EHL.

Using the ROII method, interference images in the superlubricity period corresponding to different sliding speeds were recorded. As sliding speed increases, the length of the bright tail is significantly increased. The superlubricity appears when the tail length is approximately $7 \mathrm{um}$. This point corresponds to a speed of $0.018 \mathrm{~m} / \mathrm{s}$, indicating that the hydrodynamic effect may play an important role in the superlubricity. The interference intensity in the contact area was also investigated.

The influence of sliding speed on the film thickness was explored. Film thickness is significantly increased from several $\mathrm{nm}$ to $17 \mathrm{~nm}$, which is in agreement with the EHL experimental relation between film thickness and sliding speed [28]. This implies that a hydrodynamic effect is involved in the lubrication of phosphoric acid.

Film thickness was also calculated using a numerical method based on the Reynolds equation (Eq. (3)), assuming EHL and an absolutely-smooth friction surface:

$$
\frac{\partial}{\partial x}\left(\frac{\rho h^{3}}{\eta} \frac{\partial p}{\partial x}\right)+\frac{\partial}{\partial y}\left(\frac{\rho h^{3}}{\eta} \frac{\partial p}{\partial y}\right)=-12 U \frac{\partial p h}{\partial x}
$$

where $\eta$ is the viscosity of the phosphoric acid solution, $h$ is the film thickness, $U$ is the sliding speed, $p$ is the pressure, and $x$ and $y$ are spatial coordinates.

The viscosity at pressure $p$ can be calculated using the viscosity-pressure equation $\eta=\eta_{0} e^{\alpha p}$, where $\alpha$ is the viscosity-pressure coefficient. The viscositypressure coefficient was assumed to be 0.8 or $4.4 \mathrm{GPa}^{-1}$, which is that of water and the glycerin solution with a concentration of $80 \%$, respectively. As shown in Fig. 5, there was a worn region on the silicon nitride ball; the equivalent radius $R 1$ is used instead of the origin radius of the $\mathrm{Si}_{3} \mathrm{~N}_{4}$ ball. The rule is to make the Hertz contact area of the equivalent radius $R 1$ equal to the measured contact area (in Fig. 5), as shown in Eq. (4):

$$
B=\sqrt[3]{\frac{3 W R 1}{2 E^{\prime}}}
$$

where $B$ is the radius of measured contact area, $W$ is the load and $E^{\prime}$ is the equivalent elastic modulus.

Finally, the film thickness of the phosphoric acid solution during the superlubricity period was calculated as a function of sliding speed (Fig. 8). The calculated film thickness increases with sliding speed from $3 \mathrm{~nm}$ to more than $10 \mathrm{~nm}$. Although a different viscosity-pressure coefficient is used, the calculated film thickness agrees with that measured on the whole. This indicates that the hydrodynamic effect is the dominant factor in the lubrication state of phosphoric acid.

The ratio of phosphoric acid film thickness to combined surface roughness was used to distinguish the lubrication state at different speeds [29]. Film thickness was calculated with a viscosity-pressure coefficient of $4.4 \mathrm{GPa}^{-1}$. The combined surface roughness is defined as the square root of the roughness of the sapphire plate and silicon nitride ball; thus, the combined surface roughness is $3.1 \mathrm{~nm}$. The determined lubrication state is boundary lubrication when the ratio is below 1 with a speed below $0.018 \mathrm{~m} / \mathrm{s}$, mixed lubrication when the ratio is between 1 and 3 with a speed from $0.018 \mathrm{~m} / \mathrm{s}$ to $0.048 \mathrm{~m} / \mathrm{s}$ and EHL for a ratio greater than 3 with a speed above $0.048 \mathrm{~m} / \mathrm{s}$. Superlubricity is achieved when the lubrication state is mixed lubrication or EHL. In these cases, the friction

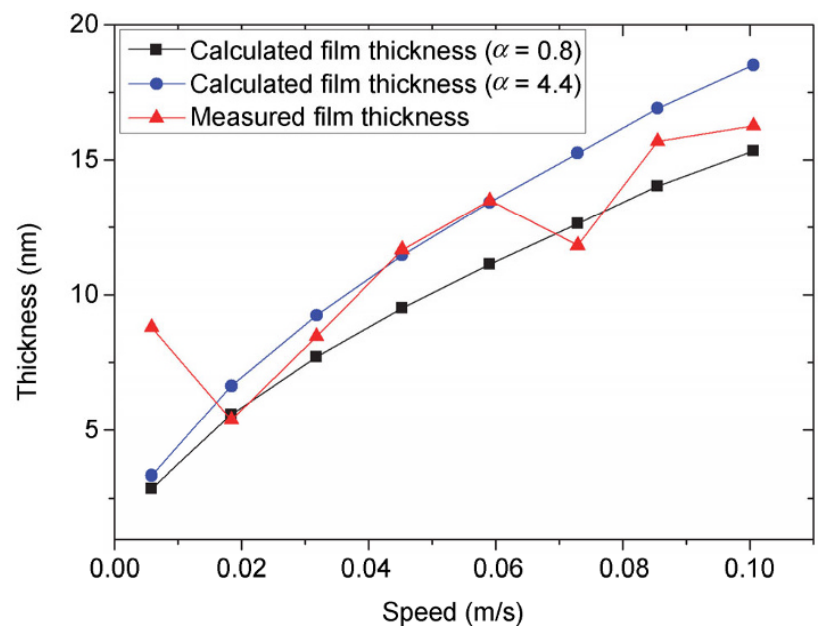

Fig. 8 The film thickness measured as a function of slide speed compared with theoretical calculation result. $\alpha$ is the viscositypressure coefficient. 
surfaces are lubricated by a hydrodynamic phosphoric acid film, and the friction caused by plowing and adhesion can be reduced.

Although the lubrication state has been determined as discussed above, the origin of the super-low friction coefficient of phosphoric acid is still unknown. When superlubricity is achieved, the film thickness is about $10 \mathrm{~nm}$ on average. The flow properties of aqueous solutions confined to nanofilms (> $3 \mathrm{~nm}$ ) can be similar to those in bulk [16]. For further investigation, the lubrication state was assumed to be EHL, and the friction coefficient was calculated using a numerical method for a speed of $0.073 \mathrm{~m} / \mathrm{s}$. The friction $F_{h}$ between the ball and the plate can be calculated as

$$
F_{h}=\left.\iint\left[\frac{1}{2} \frac{\partial p}{\partial x}(2 z-h)+\left(U_{h}-U_{0}\right) \frac{\eta}{h}\right]\right|_{z=h} \mathrm{~d} x \mathrm{~d} y
$$

where $U_{h}$ and $U_{0}$ are the speed of ball and plate, respectively.

The friction coefficient can be calculated by dividing $F_{h}$ by the load of $1.5 \mathrm{~N}$. With viscosity-pressure coefficients of 0.8 and $4.4 \mathrm{GPa}^{-1}$, the calculated friction coefficients are 0.0025 and 0.0031 , respectively. These coefficients are similar to that measured with a speed of $0.076 \mathrm{~m} / \mathrm{s}$, suggesting that superlubricity can theoretically be achieved through EHL when the superlubricity of phosphoric acid is achieved.

In the present work, only the hydrodynamic effect was taken into account. Other effects, including tribology-chemical reactions and the electric double layer effect, will also influence the superlubricity. Tribology-chemical reactions form electric double layers on silicon nitride surfaces lubricated by water; these layers would bear a part of the load [22]. Raman spectroscopy indicates that the hydrogen bond effect of phosphoric acid solution is enhanced with time, indicating that a hydrogen bond network might play a role in the superlubricity due to the super-low friction achieved by hydration on the nanometer scale [25]. This work revealed that the hydrodynamic effect plays an important role in the superlubricity of phosphoric acid in addition to the electric double layer and hydration. The mechanism of the superlubricity may be a consequence of a variety of factors; such factors require further investigation at both the macroscopic and nanometer scales.

\section{Conclusion}

In conclusion, the friction behavior of silicon nitride and sapphire lubricated by phosphoric acid were investigated with a ball-on-disk apparatus. Superlubricity is achieved with speeds from $0.012 \mathrm{~m} / \mathrm{s}$ to $0.2 \mathrm{~m} / \mathrm{s}$. The wear mainly occurs during the running-in period and disappears when the super-low friction state comes into being. During the running-in period, a large friction coefficient results from the boundary lubrication regime. Both experimental results and numerical simulation suggest that superlubricity appears when phosphoric acid is in either a mixed lubrication or an EHL state. The hydrodynamic effect plays an important role in the achievement of superlubricity between ceramic and sapphire across phosphoric acid.

\section{Acknowledgement}

The work is financially supported by the National Key Basic Research (973) Program of China (No. 2013CB934200), and the National Natural Science Foundation of China (Nos.51222507, 51335005, 51321092).

Open Access: This article is distributed under the terms of the Creative Commons Attribution License which permits any use, distribution, and reproduction in any medium, provided the original author(s) and source are credited.

\section{Reference}

[1] Hirano M, Shinjo K. Atomistic locking and friction. Phys Rev B 41(17): 11837 (1990)

[2] Erdemir A, Martin J M. Superlubricity. Elsevier: New York, 2007.

[3] Martin J M, Donnet C, Lemogne T, Epicier T. Superlubricity of molybdenum-disulfide. Phys Rev B 48: 10583-10586 (1993)

[4] Chhowalla M, Amaratunga G A J. Thin films of fullerene like $\mathrm{MoS}_{2}$ nanoparticles with ultra-low friction and wear. Nature 407(6801): 164-167 (2000)

[5] Heimberg J A, Wahl K J, Singer I L, Erdemir A. Superlow friction behavior of diamond-like carbon coatings: Time and speed effects. Appl Phys Lett 78(17): 2449-2451 (2001) 
[6] Sutton D C, Limbert G, Stewart D, Wood R J K. The friction of diamond-like carbon coatings in a water environment. Friction 1(3): 210-221 (2013)

[7] Dienwiebel M, Verhoeven G S, Pradeep N, Frenken J W M, Heimberg J A, Zandbergen H W. Superlubricity of graphite. Phys Rev Lett 92(12): 126101 (2004)

[8] Khurshudov A, Kato K, Sawada D. Tribological and mechanical properties of carbon nitride thin coating prepared by ion-beam-assisted deposition. Tribol Lett 2(1): 13-21 (1996)

[9] Wang D F, Kato K. Coating hardness effect on the critical number of friction cycles for wear particle generation in carbon nitride coatings. Diam Relat Mater 11(11): 18171830 (2002)

[10] Zhang R, Ning Z, Zhang Y, Zheng Q, Chen Q, Xie H, Qian W, Wei F. Superlubricity in centimetres-long double-walled carbon nanotubes under ambient conditions. Nat Nanotechnol 8: 912-916 (2013)

[11] Socoliuc A, Bennewitz R, Gnecco E, Meyer E. Transition from stick-slip to continuous sliding in atomic friction: Entering a new regime of ultralow friction. Phys Rev Lett 92(13): 134301 (2004)

[12] Sun C Q, Sun Y Ni, Y G, Zhang X, Pan J S, Wang X H, Zhou J, Li L T, Zheng W T, Yu S S, Pan L K, Sun Z. Coulomb repulsion at the nanometer-sized contact: A force driving superhydrophobicity, superfluidity, superlubricity, and supersolidity. J Phys Chem C 113(46): 20009-20019 (2009)

[13] Hrano M, Shinjo K, Kaneko R, Murata Y. Observation of superlubricity by scanning tunneling microscopy. Phys Rev Lett 78(8): 1448-1451 (1997)

[14] Wong H C, Umehara N, Kato K. Frictional characteristics of ceramics under water-lubricated conditions. Tribol Lett 5(4): 303-308 (1998)

[15] Chen M, Kato K, Adachi K. Friction and wear of self-mated $\mathrm{SiC}$ and $\mathrm{Si}_{3} \mathrm{~N}_{4}$ sliding in water. Wear 250(1): 246-255 (2001)

[16] Uri R, Laurat P, Klein J. Fluidity of water confined to subnanometre films. Nature 413(6851): 51-54 (2001)
[17] Chen M, Briscoe W H, Armes S P, Klein J. Lubrication at physiological pressures by polyzwitterionic brushes. Science 323(5922): 1698-1701 (2009)

[18] Ma Z Z, Zhang C H, Luo J B, Lu X C, Wen S Z. Superlubricity of a mixed aqueous solution. Chinese Phys Lett 28(5): 056201 (2011)

[19] Li J, Liu Y, Luo J, Liu P, Zhang C. Excellent lubricating behavior of brasenia schreberi mucilage. Langmuir 28(20): 7797-7802 (2012)

[20] Arad S, Rapoport L, Moshkovich A, van Moppes D, Karpasas M, Golan R, Golan Y. Superior biolubricant from a species of red microalga. Langmuir 22(17): 7313-7317 (2006)

[21] Wang X, Kato K, Adachi K. The critical condition for the transition from HL to ML in water-lubricated SiC. Tribol Lett 16(4): 253-258 (2004)

[22] Xu J G, Kato K. Formation of tribochemical layer of ceramics sliding in water and its role for low friction. Wear 245(1): 61-75 (2000)

[23] Klein J. Hydration lubrication. Friction 1(1): 1-23 (2013)

[24] Li J, Zhang C, Luo J. Superlubricity behavior with phosphoric acid-water network induced by rubbing. Langmuir 27(15): 9413-9417 (2011)

[25] Li J, Ma L, Zhang S, Zhang C, Liu Y, Luo J. Investigations on the mechanism of superlubricity achieved with phosphoric acid solution by direct observation. J Appl Phys 114(11): 114901 (2013)

[26] Ma L, Zhang C. Discussion on the technique of relative optical interference intensity for the measurement of lubricant film thickness. Tribol Lett 36(3): 239-245 (2009)

[27] Choo J W, Olver A V, Spikes H A. The influence of transverse roughness in thin film, mixed elastohydrodynamic lubrication. Tribol Int 40(2): 220-232 (2007)

[28] Chapkov A D, Bair S, Cann P, Lubrecht A A. Film thickness in point contacts under generalized Newtonian EHL conditions: Numerical and experimental analysis. Tribol Int 40(10), 1474-1478 (2007)

[29] Luo J, Lu X, Wen S. Developments and unsolved problems in nano-lubrication. Prog Nat Sci 11(3): 173-183 (2001) 


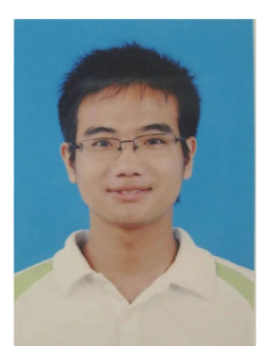

Mingming DENG. He received his Bachelor degree in mechanical engineering in 2012 from University of Science and Technology of China,

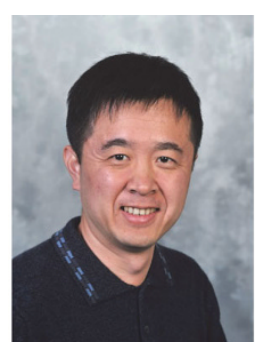

Chenhui ZHANG. He received his PhD degree in mechanical engineering from Tsinghua University, Beijing, China in 2004. From then, he worked at the State Key Laboratoty of Tribology at Tsinghua. From February 2011 to August 2011, he was invited to Lulea University of
Hefei, China. Now he is a PhD candidate in mechanical engineering at Tsinghua University. His research area is mainly about the water based superlubricity.

Technology in Sweden as a visiting scholar. Then he was invited to Weizmann Institute of Science in Israel as a visiting scientist from February 2012 to January 2013. His current position is an associate professor at Tsinghua University. His research areas cover surface coatings technology and lubrication theory. His current research interest focuses on the water based lubrication and superlubricity. 